\title{
Anaphylaxis avoidance and management: educating patients and their caregivers
}

This article was published in the following Dove Press journal:

Journal of Asthma and Allergy

10 July 2014

Number of times this article has been viewed

\section{Kirsi M Järvinen \\ Jocelyn Celestin}

Division of Allergy and Immunology, Department of Medicine, Albany Medical College, Albany, NY, USA
Correspondence: Kirsi M Järvinen-Seppo Division of Allergy and Immunology and Center for Immunology and Microbial Diseases, Albany Medical College, 47 New Scotland Ave, MC \# I5I, Albany, NY, USA

Tel +I 5182629824

Fax +| $518262616 \mid$

Email jarvink@mail.amc.edu
Abstract: Anaphylaxis is an increasingly prevalent problem in westernized countries. Therefore, it is of utmost importance that the increasing numbers of patients at risk for anaphylaxis receive proper education on the etiology and risk factors as well as appropriate treatment of anaphylaxis with epinephrine. The physician's role is crucial in order to educate the patients and care takers on effective measures to prevent anaphylaxis and empower them to take charge of early recognition and proper management of an anaphylactic reaction to prevent poor outcomes. This review summarizes the clinical presentation, triggers, avoidance, and management of anaphylaxis.

Keywords: food allergy, drug allergy, Hymenoptera, latex

\section{Introduction}

Anaphylaxis has been defined as "a serious allergic reaction that is rapid in onset and may cause death". ${ }^{1}$ In two recent cross-sectional, random-digit telephone surveys in a predominantly adult population in the United States, the incidence of anaphylaxis was estimated to be probable in $5.1 \%$, and likely in $1.6 \%$ of participants. ${ }^{2}$ In an older study, the incidence of anaphylaxis was reported to be 21 per 100,000 person-years, and the occurrence rate to be 30 per 100,000 person-years. ${ }^{3}$ The rate of triggers varies between studies and age groups, but food-induced anaphylaxis is the leading single cause of anaphylaxis treated in emergency departments in the United States, especially in childhood; while drugs and insect venom are more common triggers for adults. As an example, food-induced anaphylaxis represents $15 \%-57 \%$ of cases of anaphylaxis presenting to the emergency department ${ }^{4}$ and up to $50 \%-80 \%$ of anaphylactic reactions in children. ${ }^{5,6}$ It has been estimated that up to 200 deaths are due to food-induced anaphylactic reactions, ${ }^{7}$ while 40-50 fatal stings occur each year in the United States. ${ }^{8}$ Admission rates of anaphylaxis showed a fourfold increase between 1990 and 2006 in children in the state of New York, ${ }^{9}$ suggesting that anaphylaxis is on the rise.

\section{Clinical presentation}

The majority of reactions occur within 1 hour of exposure, but the onset of symptoms may occur a few hours after exposure to the ingested allergen. ${ }^{7}$ Pathophysiologically, anaphylaxis is triggered by allergens binding to allergen-specific immunoglobulin $\mathrm{E}(\operatorname{IgE}){ }^{10}$ The allergens bind to high-affinity IgE receptors present on the surface of sensitized effector cells such as mast cells (in tissues) and basophils (in peripheral blood). Aggregation and cross-linking of the receptor lead to a signaling cascade, triggering the release of preformed and newly synthesized mediators from mast cell and basophil 
granules. These mediators exert effects on a host of different target organs, leading to the clinical manifestations of anaphylaxis. Reactions that clinically resemble anaphylaxis but are not mediated by specific IgE antibodies are considered to be anaphylactoid. Anaphylactoid reactions such as those caused by radiographic contrast material may be difficult to differentiate clinically from anaphylactic reactions. They may be caused by direct stimulation of mast cells and respond to pretreatment regimens consisting of oral glucocorticoids, $\mathrm{H} 1$ and $\mathrm{H} 2$ antihistamines, and adrenergic drugs such as ephedrine. ${ }^{11}$

Systemic reactions cause signs and symptoms in at least two organ systems, such as cutaneous (generalized hives, angioedema, flushing, or pruritus), respiratory (throat tightness, dysphagia, hoarseness, change in voice, wheezing, cough, or difficulty breathing), circulatory (dizziness, hypotension, loss of consciousness, or shock), gastrointestinal (abdominal pain, nausea, or vomiting), or uterine cramping. Less frequently, cardiac anaphylaxis may cause vasospasm, tachyarrhythmia, or bradycardia (Table 1). The diagnosis of anaphylaxis may be missed in the absence of cutaneous symptoms. The clinical presentation may differ depending on the etiology. In food-induced anaphylaxis, symptoms from the gastrointestinal tract (vomiting, diarrhea, and abdominal cramps) are more common, whereas the cardiovascular system (hypotension, passing out, and shock) is less often affected in anaphylaxis from other causes. ${ }^{12,13}$ In venom-induced anaphylaxis, systemic reactions from a large number of stings may be caused by the toxic effects from

Table I Clinical presentation of anaphylaxis

\begin{tabular}{|c|c|}
\hline Organ system & Signs and symptoms \\
\hline Cutaneous & $\begin{array}{l}\text { Pruritus, urticaria, erythema, morbilliform rash, } \\
\text { angioedema }\end{array}$ \\
\hline Ocular & $\begin{array}{l}\text { Pruritus, eyelid edema and erythema, conjunctival } \\
\text { injection, oculorrhea }\end{array}$ \\
\hline \multicolumn{2}{|l|}{ Respiratory tract } \\
\hline Nasal & Nose/ear pruritus, rhinorrhea, sneezing, congestion \\
\hline Laryngeal & $\begin{array}{l}\text { Throat pruritus and/or tightness, stridor, } \\
\text { hoarseness, change in voice, barky cough }\end{array}$ \\
\hline Chest & Cough, wheezing, dyspnea, chest tightness, cyanosis \\
\hline \multicolumn{2}{|l|}{ Gastrointestinal } \\
\hline Oral & $\begin{array}{l}\text { Pruritus and or edema of the lips/mouth/tongue, } \\
\text { metallic taste, difficulty swallowing }\end{array}$ \\
\hline Lower GI & Nausea, vomiting, crampy abdominal pain, diarrhea \\
\hline Cardiovascular & $\begin{array}{l}\text { Tachycardia, arrhythmia, dizziness, syncope, chest } \\
\text { pain, hypotension, shock }\end{array}$ \\
\hline Neurologic & $\begin{array}{l}\text { Anxiety, change in behavior, headache, seizure, } \\
\text { urinary/fecal incontinence, altered consciousness }\end{array}$ \\
\hline Other & $\begin{array}{l}\text { Diaphoresis, uterine contractions in women, } \\
\text { sense of "pending doom" }\end{array}$ \\
\hline
\end{tabular}

Note: Modified from Wang and Sampson. ${ }^{15}$ the vasoactive substances and are clinically indistinguishable from acute systemic allergic reactions. ${ }^{14}$

The clinical presentation, including the onset of symptoms, clinical severity, and sequence of symptom progression, varies between individuals. Reactions may even vary in the same individual between episodes, depending on the amount of allergen exposed to (eg, amount of food or drug, or number of stings), age, consumption of food/ drug on an empty versus full stomach, concurrent illness, exercise, and consumption of alcohol or medications. ${ }^{15,16}$ Features of anaphylaxis also differ between children and adults. More than $90 \%$ of adults have cutaneous symptoms with anaphylaxis, whereas only $80 \%$ of children do. ${ }^{17}$ Children more often present with respiratory symptoms, whereas adults more frequently experience cardiovascular compromise. ${ }^{17}$

\section{Triggers and their avoidance Food-induced anaphylaxis}

The most common food allergens causing reactions in children include milk, eggs, wheat, soy, peanuts, tree nuts, fish, and shellfish; whereas allergies to peanuts, tree nuts, fish, and shellfish are more commonly found in adults. Peanuts, tree nuts, and shellfish are the most commonly implicated foods in anaphylaxis, although, milk and eggs have emerged among common triggers, especially in children. ${ }^{6,18}$ In addition, lipid transfer protein found in fruits such as peach is a common trigger of food-induced anaphylaxis in southern Europe. ${ }^{19}$ Lastly, Commins et $\mathrm{al}^{20}$ identified 24 patients with a history of delayed onset of anaphylaxis or urticaria occurring 3-6 hours after the ingestion of meat, who have IgE antibodies to galactose-alpha-1,3-galactose (alpha-gal), a carbohydrate commonly expressed on non-primate mammalian proteins. The diagnosis of food allergy is based on clinical history, measurement of food-specific $\operatorname{IgE}$ in the serum, by skin-prick testing, and confirmatory oral food challenge.

While most cases of pediatric anaphylaxis occur in the home, ${ }^{13,21,22}$ about $20 \%$ of the reactions in children occur at school. ${ }^{22,23}$ The first reactions to foods typically occur at home, with subsequent reactions occurring outside of the home. In comparison with initial reactions, subsequent reactions due to accidental ingestion in nut allergy are more severe, more common outside the home, and more likely to be treated with epinephrine. ${ }^{24}$ Reactions to foods in adults are more likely to happen in a restaurant. ${ }^{25}$ Food consumed from commercial catering accounts for $68 \%$ of reactions caused by nuts. ${ }^{26}$ 
Educating patients regarding dietary avoidance of the food(s) known to cause anaphylaxis is challenging but very important. Involving a dietician specialized in food allergies in the care of food allergic patients may be especially useful. Avoidance measures include reading of the package labels and understanding advisory labeling. It is likewise important to always ask questions regarding any food to be consumed. According to the FALCPA (Food Allergen Labeling Consumer Protection Act), since 2006, package labels are required by law to identify the eight major allergens (peanuts, tree nuts, milk, eggs, soy, wheat, fish, and crustaceans), in plain English. Such precautionary labeling ("may contain" and "manufactured on shared equipment/ facility with") indicates foods that patients with a history of anaphylaxis should avoid, but it is not regulated, and therefore not all products with potential for cross-contamination are similarly labeled.

Although most anaphylactic reactions occur as a result of ingested food allergens, anaphylaxis to inhaled food allergens has been reported. Published reports have described anaphylaxis from inhalation of allergens from fish, shellfish, seeds, soybeans, cereal grains, eggs, milk, and other foods by airborne exposure (ie, flour in the air and vapors during cooking or roasting). ${ }^{27}$ However, inhalation of or skin exposure to peanut butter in highly peanut-sensitized children has not been shown to elicit systemic or respiratory reactions. ${ }^{28}$

A report from the United Kingdom suggested that food allergens were responsible for up to $30 \%$ of fatal cases of anaphylaxis. ${ }^{26}$ Unfortunately, most life-threatening or fatal anaphylaxis is unpredictable. The most common risk factors include asthma (any severity, especially when poorly controlled), failure to identify a known food allergen in the meal, and previous allergic reactions to the food in question. ${ }^{6,26,29-31}$ The majority of fatal food-induced anaphylactic reactions are associated with peanuts and tree nuts, with seafood, milk, and eggs accounting for the rest. ${ }^{26,31}$ Adolescents and young adults are the age groups most at risk. ${ }^{26,31}$ Lack of timely treatment with epinephrine has been associated with fatal food-induced anaphylaxis. ${ }^{26,29-31}$ The time interval from the ingestion of the food allergen to fatal collapse averages approximately $25-35$ minutes (range: 10 minutes to 6 hours). ${ }^{26}$

\section{Anaphylaxis from insect stings and bites}

Stinging insects belong to the order Hymenoptera, which includes three families: Apidae (honeybee, bumblebee, and sweat bee), Vespidae (yellow jacket, yellow and white-faced hornet, and paper wasp), and Formicidae (fire ant and har- vester ant). In North America, the yellow jacket is the most common cause of allergic reactions, whereas paper wasp is the most common trigger in the southern coastal area of the United States. ${ }^{32}$ The worker honeybee can sting only once, because it leaves its barbed ovipositor in the skin, whereas wasps, hornets, and yellow jackets can sting multiple times. Yellow jackets and hornets are highly aggressive, and yellow jackets sting mainly in the fall. Paper wasps are less aggressive, but sting when disturbed. Honeybees and bumblebees are docile and generally do not sting. Stings of the imported fire ant (IFA) are frequent in the southern and south central United States. Fire ants build nests in mounds of fresh soil that can be 1-2 feet in diameter and elevated at least several inches. Fire ants deliver multiple stings by anchoring their mandibles and pivoting, thereby forming sterile non-painful pseudo-pustules. IFA stings may elicit large local reactions in half of the subjects, and anaphylaxis occurs in $0.6 \%-6.0 \%{ }^{33}$ Severe anaphylactic reactions to mosquito stings are surprisingly rare with regard to the worldwide distribution of species. The diagnosis of insect-sting allergy is based on the clinical history and measurement of specific IgE antibodies in the serum and by skin-prick test.

Systemic reactions have also been reported from biting insects, such as horse flies and deer flies ${ }^{34}$ scorpions (probably under-reported), ${ }^{35,36}$ huntsman spiders, ${ }^{37}$ and ticks. ${ }^{38,39}$ There have been several deaths reported from anaphylaxis to Triatoma (kissing bug, conenose bug, and assassin bug) found throughout the desert Southwest and California. Commercial allergy tests are not readily available for biting insects.

Avoidance measures to reduce the likelihood of an insect sting include extermination of nests in the immediate vicinity of the patient's home by a professional; avoidance of wearing brightly colored or flowery prints, hair sprays, and perfumes; avoidance of walking outside without shoes; and wearing long pants and long-sleeved shirts and gloves when working outside. Bushes, eaves, attics, garbage containers, and picnics attract stinging insects, and it is recommended to be extra cautious in such situations. Stinging insects are also found in flower gardens and in areas where wild flowers are common. Striking at a yellow jacket can annoy the insect and initiate an attack. Insect repellants are of no use for stinging insects, but insecticides approved for use on insects may be utilized to kill insects from a distance. Individuals with mosquito allergy should avoid mosquito-infested areas such as tall grass, bush, wetlands, and swamps, especially at dawn and dusk, and wear protective clothing. Personal mosquito repellents, such as DEET (N,N-diethyl-m-toluamide), are effective 
against biting insects. Clothing, bed nets, and camping tents should be treated with an insecticide such as permethrin. ${ }^{40}$ Triatoma infestation of a bedroom can be controlled by the use of readily available insecticides.

\section{Drug-induced anaphylaxis}

While foods are the most common cause of anaphylaxis in children, drugs are the main cause of anaphylaxis in adults. Antibiotics, especially $\beta$-lactams, aspirin, or non-steroidal anti-inflammatory drugs (NSAIDs) are most commonly implicated in drug-induced adult anaphylaxis. ${ }^{41}$ In spite of the high prevalence of drug-induced anaphylaxis in the adult population, adequate and reliable skin testing materials to document IgE-mediated reactions are available only for penicillin. Consequently, the diagnosis for IgE-mediated sensitivity for most drugs relies mainly on the clinical history and challenge with the drug in question.

\section{$\beta$-lactam antibiotics}

Whereas a history of "penicillin allergy" is very common, approximately $90 \%$ of patients who claim a history of "penicillin allergy" are able to tolerate penicillin without any problem. ${ }^{42}$ Yet, patients with a history of penicillin allergy should be evaluated by an allergist before penicillin is prescribed. About $97 \%$ of patients who test negative with a mixture of penicillin $G$ and penicilloyl-polylysine can be safely treated with penicillin. Patients who test positive should be either desensitized or treated with a non- $\beta$-lactam antibiotic. $^{43}$

Although cephalosporins and penicillin share a common $\beta$-lactam ring, the history of penicillin allergy is not a contraindication for the administration of cephalosporins. ${ }^{44}$ However, in penicillin skin-test-positive patients, the risk of a reaction to a cephalosporin is about $6 \%$ compared with less than $1 \%$ in a referent population. ${ }^{45}$ Because there have been fatalities in patients with a history of penicillin allergy who have received cephalosporins without being tested for penicillin, all patients with a history of penicillin allergy should be evaluated and, if indicated, tested for penicillin before receiving cephalosporins. If the skin test is positive, then the patient should undergo a graded challenge or be desensitized. ${ }^{46}$

Patients who are skin-test-positive for penicillin can safely receive the monobactam aztreonam. ${ }^{47}$ Aztreonam has no cross-reactivity with other $\beta$-lactams, except for ceftazidime. On the other hand, patients who are truly allergic to aztreonam can safely receive a $\beta$-lactam, except ceftazidime. Both, meropenem and imipenem are well tolerated in penicillin skin-test-positive patients who have a negative skin test to imipenem. ${ }^{48}$ However, patients with a history of penicillin allergy with a positive skin test to penicillin who require imipenem should receive it by graded challenge.

\section{Aspirin and NSAIDs}

Most of the reactions associated with aspirin and NSAIDs, which may involve the respiratory (rhinorrhea, nasal congestion, and asthma), dermatological (hives and angioedema), and cardiovascular (arrhythmia, hypotension, and shock) systems are not IgE-mediated. Therefore, it is more appropriate to call them anaphylactoid rather than anaphylactic. Because those reactions are not IgEmediated, they cannot be diagnosed or confirmed by skin testing. They are more likely associated with elevation of the levels of cysteinyl leukotrienes due to the inhibition of cyclooxygenase enzyme from the eosinophils and mast cells of aspirin or NSAID-sensitive patients. ${ }^{49}$ However, most patients who react to ASA (acetylsalicylic acid), a primary inhibitor of COX-1, are able to tolerate celecoxib, a selective COX-2 inhibitor. ${ }^{50}$

\section{Chemotherapeutic agents}

Currently, one of the most studied chemotherapeutic agents associated with anaphylaxis are the platinum-containing agents. Both, IgE-mediated and anaphylactoid reactions can occur with cisplatin and carboplatinum. A positive skin test may indicate the presence of specific $\operatorname{IgE}$ antibodies for these drugs. Effective desensitization protocols have been put in place in recent years, and most patients who have had reactions to and are in need of those drugs to treat their cancer, can be effectively desensitized and treated. ${ }^{51}$

\section{Monoclonal antibodies and biological modifiers}

Anaphylactic reactions have been associated with monoclonal antibodies and biological modifiers. The risk of anaphylaxis with omalizumab is $0.2 \%$. It is recommended that patients wait 2 hours after the first three injections of omalizumab, which can also be associated with a delayed and protracted form of anaphylaxis. ${ }^{52}$ Patients receiving omalizumab should carry an epinephrine autoinjector with them at all times. ${ }^{53}$

A number of reactions have been described in patients receiving infliximab. The majority of reactions are not IgEmediated, but due to direct activation of mast cells, ${ }^{54}$ they can be pretreated with steroids, antihistamines, and antipyretics. Also, it has been observed that loading in three separate doses given at week 0,2 , and 6 is less immunogenic than 
administering a single high-loading dose. Also, patients who are treated regularly are less likely to have reactions than patients who are treated on demand. Finally, patients who have no reasonable alternatives to infliximab can be successfully desensitized. ${ }^{55}$

\section{Anaphylaxis to radiocontrast media}

Adverse reactions to radiocontrast media ( $\mathrm{RCM}$ ) occur in $5 \%-8 \%$ of the patients who undergo radiological examinations. The reactions to RCM are anaphylactoid in nature. They may involve the direct stimulation of mast cells by the osmotic load, and at-risk patients can be successfully pre-medicated with $50 \mathrm{mg}$ of oral prednisone 13, 7, and 1 hour prior to the procedure in addition to $50 \mathrm{mg}$ of diphenhydramine and 25 mg of ephedrine given orally before the procedure. ${ }^{11}$ With the advent of low osmolar RCM, the incidence of severe life-threatening reactions has decreased tenfold, from $1 \%$ to $0.1 \%{ }^{56}$ The common belief that there is a correlation between shellfish sensitivity and susceptibility to RCM is a myth.

\section{Latex-induced anaphylaxis}

Anaphylactic reactions to latex are due to the formation of $\mathrm{IgE}$ antibodies to the antigens of Hevea brasiliensis, the source of latex. About $17 \%$ of all intraoperative anaphylaxis is due to latex, especially among health care workers and patients with spina bifida. ${ }^{57}$ Patients are usually sensitized after prolonged contact with latex protein through the wearing of latex gloves with powder, latex condom use, or via multiple surgical procedures. In contrast to anaphylaxis due to nonsurgical procedures, intraoperative latex-induced anaphylaxis is characterized by profound hypotension and cardiovascular collapse. ${ }^{58}$ There are no standardized testing materials to skin test patients with latex allergy. A radioallergosorbent test is available, but it has variable sensitivity and specificity. When it is negative, some practitioners have used a non-approved homemade latex extract, which may contain variable amounts of latex. ${ }^{59}$ Patients who are sensitive to latex should avoid products containing latex and environments that are not latex-free, and carry an epinephrine autoinjector with them at all times.

\section{Perioperative anaphylaxis}

A number of agents administered in the perioperative period, such as muscle relaxants, inducers, antibiotics, volume expanders, narcotics, sedatives, and anticoagulants, may cause anaphylaxis or anaphylactoid reactions. Neuromuscular blocking agents are the most common cause of preoperative anaphylaxis and account for two-thirds of the reactions. Those reactions are associated with the tertiary or quaternary ammonium group, such as pancuronium and vecuronium, ${ }^{60}$ to which specific IgE antibodies have been demonstrated. There is a lot of cross-reactivity between muscle relaxant agents ${ }^{61}$ and a variety of agents that may be used during anesthesia, such as acetylcholine, morphine, and pentolinium. The barbiturate anesthesia thiopental is rarely associated with anaphylaxis. ${ }^{62}$

Intraoperative anaphylaxis may be difficult to diagnose for a variety of reasons. The patient is unconscious and cannot express the typical symptoms associated with anaphylaxis, such as itching and flushing. The hives may be covered by the surgical drapes, and the observed bradycardia and cardiopulmonary collapse may be attributed to other causes. ${ }^{63}$ There are a number of agents administered to patients before, during, and after surgery that have high potential of causing anaphylaxis or anaphylactoid reactions. $\beta$-lactam antibiotics and vancomycin are the most commonly implicated antibiotics during anesthesia. While $\beta$-lactams may cause an IgEmediated reaction, vancomycin on the other hand primarily causes infusion-rate-dependent direct histamine release from the mast cells. Therefore, reducing the rate of infusion can virtually eliminate vancomycin-related reactions. ${ }^{64}$ Also opioid narcotics directly stimulate dermal mast cells. Largemolecular-weight volume expanders such as dextran are rarely the cause of intraoperative anaphylaxis. ${ }^{65}$ Protamine, an agent used to reverse the effect of heparin may cause both anaphylaxis and anaphylactoid reactions. Finally, most reactions ascribed to local anesthetic agents are due to the direct effects of the agents rather than through identifiable immune mechanisms.

\section{Management}

Epinephrine is the drug of choice for the treatment of anaphylaxis ${ }^{1,66,67}$ and should be injected promptly in the event of an anaphylactic reaction or when progression to anaphylaxis is likely. It is controversial whether an individual with generalized acute urticaria has anaphylaxis. ${ }^{68}$ Generalized acute urticaria itself is not a life-threatening symptom, yet in the context of a known exposure to an allergen that has previously triggered anaphylaxis, the recommendation for an exposure outside of a medical setting is to inject epinephrine. ${ }^{69}$

Epinephrine is a direct-acting sympathomimetic agent that increases vasoconstriction, inotropy/chronotropy, and bronchodilation and decreases mucosal edema. Epinephrine downregulates mast-cell release of histamine and other 
mediators of inflammation, unlike other drugs including antihistamines and inhaled bronchodilators used to treat symptoms of allergic reactions. By blocking the histamine receptors, $\mathrm{H} 1$ and $\mathrm{H} 2$ antihistamines can prevent the progression of symptoms, but they do not prevent the release of histamine. Therefore, antihistamines alleviate hives and rhinorrhea, but have a slow onset of action (1 or more hours), and do not relieve respiratory symptoms or shock. ${ }^{67}$ Inhaled bronchodilators may be used as an adjunct therapy for lower airway symptoms, but cannot be relied upon in anaphylaxis because they do not relieve upper airway constriction or shock. Given their slow onset of action, corticosteroids have not been evaluated and are unlikely to contribute substantially to the acute treatment of anaphylaxis, although they are routinely used to prevent delayed or biphasic allergic manifestations. ${ }^{1}$ If given, the dosing of intravenous corticosteroids should be equivalent to $1.0-2.0 \mathrm{mg} / \mathrm{kg}$ per dose of methylprednisolone every 6 hours. Oral administration of prednisone, $1.0 \mathrm{mg} / \mathrm{kg}$, up to $50 \mathrm{mg}$ might be sufficient for milder attacks.

Prompt use of epinephrine in the field has been shown to decrease the need for hospital admission for anaphylaxis in children, whereas delayed administration of epinephrine has been identified as a risk factor for fatal food-induced anaphylaxis. ${ }^{26,30,31,66,70,71}$ The recommended dose of epinephrine is $0.01 \mathrm{mg} / \mathrm{kg}$ (maximum of $0.3-0.5 \mathrm{mg}$ ), which can be repeated every 5-20 minutes. ${ }^{69,72}$ Epinephrine is available in autoinjectable devices (eg, Epipen ${ }^{\circledR}$ [Mylan Inc, Basking Ridge, NJ, USA]/Adrenaclick ${ }^{\circledR}$ [Amedra Pharmaceuticals, Horsham, PA, USA]/Auvi-Q ${ }^{\circledR}$ [Sanofi-Aventis, Bridgewater, NJ, USA]) containing preset doses of either 0.15 or $0.3 \mathrm{mg}$ of epinephrine per injection. The devices are designed for self-administration or for administration by a companion as a "first-aid" treatment, but patients should seek prompt professional treatment immediately following administration of epinephrine. Some patients may be relatively resistant to treatment. Occasionally, more than one dose of epinephrine is needed, and this has been shown to be the case in 10\%-19\% of food-induced anaphylactic reactions in mixed and pediatric populations. ${ }^{18,22,73}$

Advanced care for anaphylaxis should be sought promptly after epinephrine injection for first-aid treatment of anaphylaxis. This can be done by calling 911 (or other country equivalent) for additional care and emergency transport to a hospital/emergency department; subjects with anaphylaxis should not be taken to advanced care by private car. The observation period needs to individualized, typically 4-6 hours at a minimum after symptoms have resolved, because there are no reliable methods of predicting biphasic or protracted anaphylaxis. ${ }^{72}$ Bronchodilators can aid with the bronchoconstriction. Airway patency should be established, and patients with respiratory or circulatory compromise should receive oxygen and be placed in the supine position. Chest pain may be a sign of coronary ischemia or esophageal edema. Hypotensive reactions not responding promptly to intramuscular epinephrine may require intravenous fluids and cautious intravenous administration of diluted epinephrine or another vasopressor. Patients on $\beta$-receptor blocker therapy may be resistant to usual doses of epinephrine and intravenous fluids, and may benefit from glucagon.

With bee stings, several chemicals referred to as pheromones are released, exciting further sting responses by other bees in the area. These chemicals can be washed off with water. After finding the stinger in the skin, it should be carefully removed by flicking it upward, away from the skin, avoiding compression of the venom sac, which could introduce additional venom into the victim.

\section{Biphasic reactions}

In addition to uniphasic reactions, although rare, there are delayed onset, protracted, persistent, and biphasic reactions. The severity of the late-phase symptoms could be either more or less prominent than the initial reaction. ${ }^{74}$ In biphasic reactions, symptoms recur after resolution of the initial event in 1-72 hours, with most developing within 8 hours; in protracted reactions, symptoms do not respond to treatment and may last up to 72 hours. ${ }^{30,74,75}$ Biphasic reactions have been reported in 3\%-20\% of anaphylactic reactions in adults and mixed age populations to both oral and parenteral agents. ${ }^{75}$ In the pediatric population, the incidence of biphasic reactions has been lower $(2 \%-6 \%){ }^{21,76}$

Risk factors for a biphasic response include orally administered allergens, delayed onset of initial symptoms after antigen exposure ( $>30$ minutes), prior $\beta$-blockade, delay or inadequate amount of epinephrine given for the first response, or the requirement of large doses of epinephrine. ${ }^{75}$ Failure to administer corticosteroids may predispose to a biphasic response, although this has not been conclusively shown. The mechanisms of biphasic reactions are improperly understood. ${ }^{74,77}$

\section{Education}

All patients at risk for anaphylaxis from food or Hymenoptera should be educated about the signs and symptoms of anaphylaxis. They should be instructed regarding the correct use of an epinephrine autoinjector, be provided with written instructions on its proper administration, and have an anaphylaxis treatment plan. Intramuscular injection of epinephrine 
into the lateral thigh (vastus lateralis) is the preferred route for therapy in first-aid treatment. The injection may be given through clothing, avoiding obstructions such as seams or items in pockets. Proper storage of the epinephrine, away from extremes of temperature and direct sunlight to protect the drug from degradation, is also important. Emergency kits are no substitute for emergency medical attention and every patient should be seen by a medical professional and observed under medical supervision for a minimum of 4 hours after resolution of the symptoms. It is important to demonstrate and return-demonstrate the use of epinephrine autoinjector frequently, as it has been shown that patients forget the proper technique in as little as 3 months.

With food allergy, it is recommended that autoinjectors with $0.15 \mathrm{mg}$ of epinephrine are prescribed for otherwise healthy young children who weigh $10-25 \mathrm{~kg}(22-55 \mathrm{lb})$ and autoinjectors with $0.30 \mathrm{mg}$ of epinephrine for those who weigh approximately $25 \mathrm{~kg}$ (55 lb) or more. ${ }^{68}$ In other cases for anaphylaxis, the general recommended weight for the higher dose of epinephrine is $30 \mathrm{~kg}(66 \mathrm{lb})$. For children who weigh less than $10 \mathrm{~kg}(22 \mathrm{lb})$, the physician and family should weigh the risks of delay in dosing or possible dosing errors when an ampule/syringe/needle is used against accepting a non-ideal autoinjector dose. Up to $16 \%-35 \%$ of anaphylactic reactions of various etiologies, including Hymenoptera insect stings, immunotherapy injections, and food allergies may need multiple doses of epinephrine. ${ }^{18,22,73,78-80}$ Some have suggested that patients at risk for severe anaphylaxis should always carry two doses of epinephrine, ${ }^{79}$ while others have indicated that those with food-induced anaphylaxis, ${ }^{73}$ or those with significant food allergies and asthma should do so. ${ }^{18}$ However, at present, there are no official guidelines on when to prescribe more than one autoinjectable epinephrine device. The second dose of epinephrine should be administered if anaphylactic symptoms persist beyond 10 minutes.

It may not be easy to identify which patients will need a self-injectable epinephrine device, except for those with a previous episode of anaphylaxis that was characterized by respiratory or cardiovascular compromise. Skin manifestations such as urticaria, angioedema, flushing, or itching occur in more than $80 \%$ of children with anaphylaxis; however, acute generalized urticaria and angioedema alone may not necessarily warrant a diagnosis of "anaphylaxis" (a point of controversy). Patients with food allergy who should be prescribed an epinephrine autoinjector include those with a history of a prior systemic allergic reaction, those with asthma, or those with a known food allergy to peanuts, tree nuts, fish, and crustacean shellfish (ie, allergens known to be associated with more fatal and near-fatal allergic reactions). In addition, consideration should be given to prescribing an epinephrine autoinjector for all patients with food allergy having IgE-mediated reactions, because the severity of any subsequent reactions is unpredictable. In venom anaphylaxis, self-injectable epinephrine should be prescribed for a child who has experienced generalized acute urticaria after an insect sting, because of the $10 \%$ risk of a more severe reaction from a future sting. ${ }^{81}$ Some "high-risk" circumstances may justify prescription of self-injectable epinephrine in the absence of previous anaphylaxis in individuals with confirmed allergy to venom. These include history of asthma, likely repeat exposures, and living in remote areas far away from emergency medical care. ${ }^{72}$

Approach to effective care also requires a comprehensive plan involving schools, camps, and other youth organizations, as well as education of supervising adults in regards to proper recognition and treatment of anaphylaxis. It is paramount to educate patients about the potential for severe reactions, even in the absence of previous severe reactions, although it has not been shown that each following reaction would be more severe than the preceding one (a common misbelief). Wearing a medical identification bracelet or necklace is also recommended. Lastly, the anticipation of unforeseen accidental exposures together with the knowledge of potential fatal outcome of an anaphylactic reaction has a significant impact on quality of life, which needs special attention in some patients. ${ }^{82}$

\section{Specific therapies Venom immunotherapy}

Venom immunotherapy (VIT) is recommended for patients who have experienced a systemic reaction after an insect sting and shown evidence of specific IgE to venom allergens. ${ }^{81}$ However, VIT is generally not necessary for children 16 years of age and younger who have experienced only a systemic cutaneous reaction (generalized hives) without other systemic manifestations to Hymenoptera, but might be considered for children who have experienced one to fire ants. ${ }^{81}$ VIT is available with all five available Hymenoptera venom extracts. Immunotherapy with whole body extract of IFA is also available and has shown efficacy in clinical studies, although it is variable in allergen content. ${ }^{14}$

VIT has been shown efficacious in preventing a subsequent systemic sting reaction in $95 \%$ of stinging-insect sensitive patients. ${ }^{81}$ Injections are generally administered at weekly intervals until a maintenance dose is achieved, and typically 4-week intervals can thereafter be applied. VIT is usually continued for at least $3-5$ years. The major risk of VIT 
as with other types of immunotherapy is anaphylaxis, with an incidence of up to $12 \%{ }^{83}$ Large local reactions occurring at the injection site are more common and can be treated with oral antihistamines as needed.

\section{Future therapies for food allergy}

Currently, the only treatment for food-induced anaphylaxis is strict dietary avoidance. Therapies to prevent foodinduced anaphylaxis are under vigorous investigation. Promising therapies under investigation can be divided into allergen-specific and non-specific ones. Non-specific therapies for food-induced anaphylaxis under investigation include anti-IgE antibody, which increases the threshold dose for peanuts in peanut-allergic individuals, ${ }^{84}$ and Chinese herbal medications, which have been shown to prevent peanut-anaphylaxis in an animal model $;{ }^{85}$ human studies are underway. Allergen-specific therapies include oral, sublingual, and epicutaneous immunotherapy (desensitization), ${ }^{86}$ which may be combined with anti-IgE antibody therapy for improved safety and efficacy, although this remains to be seen. ${ }^{87}$ Allergen-specific therapies mostly in preclinical trials include mutated recombinant proteins, which are engineered in their IgE-binding activity, native and mutated allergens coadministered with bacterial adjuvants to generate maximum immune response, gene therapy, and peptide immunotherapy. ${ }^{86}$

\section{Conclusion}

Anaphylaxis is an increasingly prevalent problem in westernized countries. It is underdiagnosed, under-reported, and undertreated. ${ }^{88}$ Therefore, it is of utmost importance that the increasing numbers of patients at risk for anaphylaxis receive proper education on the etiology and risk factors, as well as appropriate treatment of anaphylaxis with epinephrine. The physician's role is crucial in order to educate the patients and caretakers on effective measures to prevent anaphylaxis and empower them to take charge of early recognition and proper management of an anaphylactic reaction to prevent poor outcomes.

\section{Acknowledgment}

The project described was supported by Grant Number K08 AI091655 (KM Järvinen) from the National Institute of Allergy and Infectious Diseases. The content is solely the responsibility of the authors and does not necessarily represent the official views of the National Institute of Allergy and Infectious Diseases or the National Institutes of Health.

\section{Disclosure}

The authors have no conflict of interest.

\section{References}

1. Sampson HA, Munoz-Furlong A, Campbell RL, et al. Second symposium on the definition and management of anaphylaxis: summary report - second National Institute of Allergy and Infectious Disease/ Food Allergy and Anaphylaxis Network symposium. J Allergy Clin Immunol. 2006;117(2):391-397.

2. Wood RA, Camargo CA Jr, Lieberman P, et al. Anaphylaxis in America: the prevalence and characteristics of anaphylaxis in the United States. J Allergy Clin Immunol. 2014;133(2):461-467.

3. Yocum MW, Butterfield JH, Klein JS, Volcheck GW, Schroeder DR, Silverstein MD. Epidemiology of anaphylaxis in Olmsted County: a population-based study. J Allergy Clin Immunol. 1999;104: 452-456.

4. Keet CA, Wood RA. Food allergy and anaphylaxis. Immunol Allergy Clin North Am. 2007;27(2):193-212, vi.

5. Simons FER, Chad ZH, Gold M. Anaphylaxis in children: real-time reporting from a national network. Allergy Clin Immunol Int. 2004(Suppl):242-244.

6. Colver AF, Nevantaus H, Macdougall CF, Cant AJ. Severe food-allergic reactions in children across the UK and Ireland, 1998-2000. Acta Paediatr. 2005;94(6):689-695.

7. Sampson HA. Anaphylaxis and emergency treatment. Pediatrics. 2003;111(6 Pt 3):1601-1608.

8. Graft DF. Insect sting allergy. Med Clin North Am. 2006;90(1): 211-232.

9. Lin RY, Anderson AS, Shah SN, Nurruzzaman F. Increasing anaphylaxis hospitalizations in the first 2 decades of life: New York State, 1990-2006. Ann Allergy Asthma Immunol. 2008;101(4):387-393.

10. Simons FE, Frew AJ, Ansotegui IJ, et al. Risk assessment in anaphylaxis: current and future approaches. J Allergy Clin Immunol. 2007; 120(Suppl 1):S2-S24.

11. Greenberger PA, Halwig JM, Patterson R, Wallemark CB. Emergency administration of radiocontrast media in high-risk patients. $J$ Allergy Clin Immunol. 1986;77(4):630-634.

12. Cianferoni A, Novembre E, Mugnaini L, et al. Clinical features of acute anaphylaxis in patients admitted to a university hospital: an 11-year retrospective review (1985-1996). Ann Allergy Asthma Immunol. 2001;87(1):27-32.

13. Novembre E, Cianferoni A, Bernardini R, et al. Anaphylaxis in children: clinical and allergologic features. Pediatrics. 1998;101(4):E8.

14. Golden DB. Insect allergy. In: Adkinson NF Jr, Yunginger JW, Busse WW, Bochner BS, Holgate ST, Simons FER, editors. Middleton's Allergy. 6th ed. Philadelphia, PA: Mosby; 2003:1475-1485.

15. Wang J, Sampson HA. Food anaphylaxis. Clin Exp Allergy. 2007;37(5):651-660

16. Pumphrey R. Anaphylaxis: can we tell who is at risk of a fatal reaction?. Curr Opin Allergy Clin Immunol. 2004;4(4):285-290.

17. Braganza SC, Acworth JP, Mckinnon DR, Peake JE, Brown AF. Paediatric emergency department anaphylaxis: different patterns from adults. Arch Dis Child. 2006;91(2):159-163.

18. Järvinen KM, Sicherer SH, Sampson HA, Nowak-Wegrzyn A. Use of multiple doses of epinephrine in food-induced anaphylaxis in children. J Allergy Clin Immunol. 2008;122(1):133-138.

19. Asero R, Antonicelli L, Arena A, et al. Causes of food-induced anaphylaxis in Italian adults: a multi-centre study. Int Arch Allergy Immunol. 2009;150(3):271-277.

20. Commins SP, Satinover SM, Hosen J, et al. Delayed anaphylaxis, angioedema, or urticaria after consumption of red meat in patients with IgE antibodies specific for galactose-alpha-1,3-galactose. J Allergy Clin Immunol. 2009;123(2):426-433.

21. Lee JM, Greenes DS. Biphasic anaphylactic reactions in pediatrics. Pediatrics. 2000;106(4):762-766. 
22. Uguz A, Lack G, Pumphrey R, et al. Allergic reactions in the community: a questionnaire survey of members of the anaphylaxis campaign. Clin Exp Allergy. 2005;35(6):746-750.

23. Rudders SA, Banerji A, Vassallo MF, Clark S, Camargo CA Jr. Trends in pediatric emergency department visits for food-induced anaphylaxis. J Allergy Clin Immunol. 2010;126(2):385-388.

24. Sicherer SH, Furlong TJ, Munoz-Furlong A, Burks AW, Sampson HA. A voluntary registry for peanut and tree nut allergy: characteristics of the first 5149 registrants. J Allergy Clin Immunol. 2001;108(1) 128-132.

25. Banerji A, Rudders SA, Corel B, Garth AM, Clark S, Camargo CA Jr. Repeat epinephrine treatments for food-related allergic reactions that present to the emergency department. Allergy Asthma Proc. 2010;31(4):308-316.

26. Pumphrey RS. Fatal anaphylaxis in the UK,1992-2001. Novartis Found Symp. 2004;257:116-128; discussion 128-132, 157-160, 276-285.

27. James JM, Crespo JF. Allergic reactions to foods by inhalation. Curr Allergy Asthma Rep. 2007;7(3):167-174.

28. Simonte SJ, Ma S, Mofidi S, Sicherer SH. Relevance of casual contact with peanut butter in children with peanut allergy. J Allergy Clin Immunol. 2003;112(1):180-182.

29. Yunginger JW, Sweeney KG, Sturner WQ, et al. Fatal food-induced anaphylaxis. JAMA. 1988;260(10):1450-1452.

30. Sampson HA, Mendelson L, Rosen JP. Fatal and near-fatal anaphylactic reactions to food in children and adolescents. $N \mathrm{Engl} \mathrm{J} \mathrm{Med}$. 1992;327(6):380-384.

31. Bock SA, Munoz-Furlong A, Sampson HA. Fatalities due to anaphylactic reactions to foods. J Allergy Clin Immunol. 2001;107(1):191-193.

32. Blanca M, Garcia F, Miranda A, et al. Determination of IgE antibodies to polistes dominulus, vespula germanica and vespa crabro in sera of patients allergic to vespids. Allergy. 1991;46(2):109-114.

33. Hoffman DR, Dove DE, Moffitt JE, Stafford CT. Allergens in hymenoptera venom. XXI. Cross-reactivity and multiple reactivity between fire ant venom and bee and wasp venoms. J Allergy Clin Immunol. 1988;82(5 Pt 1):828-834.

34. Hoffman DR. Allergic reactions to biting insects. In: Levine MI, Lockey RF, editors. Monograph on Insect Allergy. 4th ed. Milwaukee, WI: American Academy of Allergy, Asthma and Immunology; 2003:161-173.

35. Demain JG, Goetz DW. Immediate, late, and delayed skin test responses to Centruroides vittatus scorpion venom. J Allergy Clin Immunol. 1995;95(1 Pt 1):135-137.

36. More D, Nugent J, Hagan L, et al. Identification of allergens in the venom of the common striped scorpion. Ann Allergy Asthma Immunol. 2004;93(5):493-498.

37. Isbister GK. Acute allergic reaction following contact with a spider. Toxicon. 2002;40(10):1495-1497.

38. Acero S, Blanco R, Bartolome B. Anaphylaxis due to a tick bite. Allergy. 2003;58(8):824-825.

39. Bircher AJ. Systemic immediate allergic reactions to arthropod stings and bites. Dermatology. 2005;210(2):119-127.

40. Simons F, Peng Z. Mosquito allergy. In: Levine MI, Lockey RF, editors. Monograph on Insect Allergy. 4th ed. American Academy of Allergy, Asthma and Immunology; 2003:175-203.

41. Simons FE, Ardusso LR, Bilo MB, et al. World allergy organization guidelines for the assessment and management of anaphylaxis. World Allergy Organ J. 2011;4(2):13-37.

42. Gadde J, Spence M, Wheeler B, Adkinson NF Jr. Clinical experience with penicillin skin testing in a large inner-city STD clinic. JAMA. 1993;270(20):2456-2463.

43. Mendelson LM, Ressler C, Rosen JP, Selcow JE. Routine elective penicillin allergy skin testing in children and adolescents: study of sensitization. J Allergy Clin Immunol. 1984;73(1 Pt 1):76-81.

44. Goodman EJ, Morgan MJ, Johnson PA, Nichols BA, Denk N, Gold BB Cephalosporins can be given to penicillin-allergic patients who do not exhibit an anaphylactic response. J Clin Anesth. 2001;13(8): $561-564$
45. Park MA, Koch CA, Klemawesch P, Joshi A, Li JT. Increased adverse drug reactions to cephalosporins in penicillin allergy patients with positive penicillin skin test. Int Arch Allergy Immunol. 2010;153(3): 268-273.

46. DePestel DD, Benninger MS, Danziger L, et al. Cephalosporin use in treatment of patients with penicillin allergies. $\mathrm{J}$ Am Pharm Assoc (2003). 2008;48(4):530-540.

47. Saxon A, Hassner A, Swabb EA, Wheeler B, Adkinson NF Jr. Lack of cross-reactivity between aztreonam, a monobactam antibiotic, and penicillin in penicillin-allergic subjects. J Infect Dis. 1984;149(1): 16-22.

48. Romano A, Viola M, Gueant-Rodriguez RM, Gaeta F, Pettinato R, Gueant JL. Imipenem in patients with immediate hypersensitivity to penicillins. N Engl J Med. 2006;354(26):2835-2837.

49. Szczeklik A, Stevenson DD. Aspirin-induced asthma: advances in pathogenesis, diagnosis, and management. J Allergy Clin Immunol. 2003;111(5):913-921; quiz 922.

50. Stevenson DD, Simon RA. Lack of cross-reactivity between rofecoxib and aspirin in aspirin-sensitive patients with asthma. J Allergy Clin Immunol. 2001;108(1):47-51.

51. Castells MC, Tennant NM, Sloane DE, et al. Hypersensitivity reactions to chemotherapy: outcomes and safety of rapid desensitization in 413 cases. J Allergy Clin Immunol. 2008;122(3):574-580.

52. Limb SL, Starke PR, Lee CE, Chowdhury BA. Delayed onset and protracted progression of anaphylaxis after omalizumab administration in patients with asthma. J Allergy Clin Immunol. 2007;120(6): $1378-1381$.

53. Cox L, Platts-Mills TA, Finegold I, et al. American academy of allergy, asthma and Immunology/American college of allergy, asthma and immunology joint task force report on omalizumab-associated anaphylaxis. J Allergy Clin Immunol. 2007;120(6):1373-1377.

54. Candon S, Mosca A, Ruemmele F, Goulet O, Chatenoud L, Cezard JP. Clinical and biological consequences of immunization to infliximab in pediatric Crohn's disease. Clin Immunol. 2006;118(1): 11-19.

55. Lecluse LL, Piskin G, Mekkes JR, Bos JD, de Rie MA. Review and expert opinion on prevention and treatment of infliximab-related infusion reactions. Br J Dermatol. 2008;159(3):527-536.

56. Shehadi WH, Toniolo G. Adverse reactions to contrast media: a report from the committee on safety of contrast media of the international society of radiology. Radiology. 1980;137(2):299-302.

57. Alenius H, Kurup V, Kelly K, Palosuo T, Turjanmaa K, Fink J. Latex allergy: frequent occurrence of $\operatorname{IgE}$ antibodies to a cluster of 11 latex proteins in patients with spina bifida and histories of anaphylaxis. $J \mathrm{Lab}$ Clin Med. 1994;123(5):712-720.

58. Leslie Grammer PG, editor. Paterson Allergic Diseases. 7th ed. Lippincott Williams \& Wilkins; 2009.

59. Hamilton RG, Peterson EL, Ownby DR. Clinical and laboratory-based methods in the diagnosis of natural rubber latex allergy. J Allergy Clin Immunol. 2002;110(Supp1 2):S47-S56.

60. Laroche D, Lefrancois C, Gerard JL, et al. Early diagnosis of anaphylactic reactions to neuromuscular blocking drugs. Br J Anaesth. 1992;69(6):611-614.

61. Baldo BA, Fisher MM. Substituted ammonium ions as allergenic determinants in drug allergy. Nature. 1983;306(5940):262-264.

62. Baldo BA, Fisher MM. Mechanisms in IgE-dependent anaphylaxis to anesthetic drugs. Ann Fr Anesth Reanim. 1993;12(2):131-140.

63. Lieberman P, Nicklas RA, Oppenheimer J, et al. The diagnosis and management of anaphylaxis practice parameter: 2010 update. JAllergy Clin Immunol. 2010;126(3):477-480. e1-e42.

64. Cook FV, Farrar WE Jr. Vancomycin revisited. Ann Intern Med. 1978;88(6):813-818.

65. Ring J. Anaphylactoid reactions to plasma substitutes. Int Anesthesiol Clin. 1985;23(3):67-95.

66. Gold MS, Sainsbury R. First aid anaphylaxis management in children who were prescribed an epinephrine autoinjector device (EpiPen). J Allergy Clin Immunol. 2000;106(1 Pt 1):171-176. 
67. Sicherer SH, Wood RA, Stablein D, et al. Maternal consumption of peanut during pregnancy is associated with peanut sensitization in atopic infants. J Allergy Clin Immunol. 2010;126(6):1191-1197.

68. Sicherer SH, Simons FE; Section on Allergy and Immunology, American Academy of Pediatrics. Self-injectable epinephrine for firstaid management of anaphylaxis. Pediatrics. 2007;119(3):638-646.

69. Anaphylaxis in schools and other childcare settings. AAAAI Board of Directors. American Academy of Allergy, Asthma and Immunology. J Allergy Clin Immunol. 1998;102(2):173-176.

70. Bock SA, Munoz-Furlong A, Sampson HA. Further fatalities caused by anaphylactic reactions to food, 2001-2006. J Allergy Clin Immunol. 2007;119(4):1016-1018.

71. Pumphrey RS. Lessons for management of anaphylaxis from a study of fatal reactions. Clin Exp Allergy. 2000;30(8):1144-1150.

72. Joint Task Force on Practice Parameters, American Academy of Allergy, Asthma and Immunology, American College of Allergy, Asthma and Immunology, Joint Council of Allergy, Asthma and Immunology. The diagnosis and management of anaphylaxis: an updated practice parameter. J Allergy Clin Immunol. 2005;115(3 Suppl 2):S483-S523.

73. Oren E, Banerji A, Clark S, Camargo CA Jr. Food-induced anaphylaxis and repeated epinephrine treatments. Ann Allergy Asthma Immunol. 2007;99(5):429-432.

74. Lieberman P. Biphasic anaphylactic reactions. Ann Allergy Asthma Immunol. 2005;95(3):217-226; quiz 226, 258.

75. Tole JW, Lieberman P. Biphasic anaphylaxis: review of incidence, clinical predictors, and observation recommendations. Immunol Allergy Clin North Am. 2007;27(2):309-326, viii.

76. Jarvinen KM, Amalanayagam S, Shreffler WG, et al. Epinephrine treatment is infrequent and biphasic reactions are rare in food-induced reactions during oral food challenges in children. J Allergy Clin Immunol. 2009;124(6):1267-1272.

77. Lemon-Mule H, Nowak-Wegrzyn A, Berin C, Knight AK. Pathophysiology of food-induced anaphylaxis. Curr Allergy Asthma Rep. 2008;8(3):201-208.
78. Korenblat P, Lundie MJ, Dankner RE, Day JH. A retrospective study of epinephrine administration for anaphylaxis: how many doses are needed? Allergy Asthma Proc. 1999;20(6):383-386.

79. Kelso JM. A second dose of epinephrine for anaphylaxis: how often needed and how to carry. J Allergy Clin Immunol. 2006;117(2):464-465.

80. Webb LM, Lieberman P. Anaphylaxis: a review of 601 cases. Ann Allergy Asthma Immunol. 2006;97(1):39-43.

81. Moffitt JE, Golden DB, Reisman RE, et al. Stinging insect hypersensitivity: a practice parameter update. J Allergy Clin Immunol. 2004;114(4):869-886.

82. Sicherer SH, Sampson HA. Peanut allergy: emerging concepts and approaches for an apparent epidemic. J Allergy Clin Immunol. 2007;120(3):491-503; quiz 504-505.

83. Lockey RF, Turkeltaub PC, Olive ES, Hubbard JM, Baird-Warren IA, Bukantz SC. The hymenoptera venom study. III: safety of venom immunotherapy. J Allergy Clin Immunol. 1990;86(5):775-780.

84. Leung DY, Sampson HA, Yunginger JW, et al. Effect of anti-IgE therapy in patients with peanut allergy. $N$ Engl J Med. 2003;348(11): 986-993.

85. Srivastava KD, Kattan JD, Zou ZM, et al. The chinese herbal medicine formula FAHF-2 completely blocks anaphylactic reactions in a murine model of peanut allergy. J Allergy Clin Immunol. 2005;115(1): 171-178.

86. Lieberman JA, Nowak-Wegrzyn A. Vaccines and immunomodulatory therapies for food allergy. Curr Allergy Asthma Rep. 2012;12(1): 55-63.

87. Nadeau KC, Schneider LC, Hoyte L, Borras I, Umetsu DT. Rapid oral desensitization in combination with omalizumab therapy in patients with cow's milk allergy. J Allergy Clin Immunol. 2011;127(6): $1622-1624$

88. Sclar DA, Lieberman PL. Anaphylaxis: underdiagnosed, underreported, and undertreated. Am J Med. 2014;127(Suppl 1A:S1-S5).

\section{Publish your work in this journal}

The Journal of Asthma and Allergy is an international, peer-reviewed open-access journal publishing original research, reports, editorials and commentaries on the following topics: Asthma; Pulmonary physiology; Asthma related clinical health; Clinical immunology and the immunological basis of disease; Pharmacological interventions and

\section{Dovepress}

new therapies. Issues of patient safety and quality of care will also be considered. The manuscript management system is completely online and includes a very quick and fair peer-review system, which is all easy to use. Visit http://www.dovepress.com/testimonials.php to read real quotes from published authors. 